\title{
OVERALUMINISING OF NiCOCrAIY COATINGS BY Arc PVD ON Ni-BASE SUPERALLOYS
}

\author{
Lucjan Swadzba, Adolf Maciejny, Boguslaw Mendala \\ Silesian Technical University \\ Krasinskiego 8b \\ 40-019 Katowice, Poland
}

\begin{abstract}
Investigations of depositing high temperature coatings on $\mathrm{Ni}$ base superalloys by the Arc-PVD method, using exothermic reaction processes between $\mathrm{Ni}$ and $\mathrm{Al}$ with $\mathrm{NiAl}$ intermetallic formation are presented in the article. By diffusion heating at $1323 \mathrm{~K}$, a NiAl high temperature diffusion coating containing $21 \%$ at. $\mathrm{Al}$ and $50 \mu \mathrm{m}$ thick was obtained. In the next stage coatings with more complex chemical composition- NiCoCrAlY were formed. The NiCoCrAIY coatings were made with two targets. Good consistence between the chemical composition of the targets and a uniform distribution of elements in the coatings was shown. Then the surface was also covered with aluminium by the Arc-PVD method. In the vacuum chamber of the equipment a synthesis reaction between $\mathrm{NiCoCrAlY}$ and $\mathrm{Al}$ with the formation of NiAl intermetallics of high $\mathrm{Co}, \mathrm{Cr}, \mathrm{Y}$ content was initiated. The final heat treatment of coatings was conducted in air and vacuum at $1323 \mathrm{~K}$. Strong segregation of yttrium into the oxide scale in the specimens heated in air was shown. It was possible to obtain $\mathrm{NiAl}$ intermetallics phase coatings modified by $\mathrm{Co}, \mathrm{Cr}$ and $\mathrm{Y}$ by the Arc-PVD method. The coatings wcre formed on cast $\mathrm{Ni}$ base superalloy ZS6K and single crystal CMSX-4. An example of the application of this method for the aircraft engine turbine blades was presented.
\end{abstract}




\section{Introduction}

Diffusion coatings with an aluminide base are widely used to protect stationary and aircraft gas turbines against high temperature corrosion [1-5]. One of the limitations characterising those coatings is that during their formation, great amounts of elements, included in the coated alloy composition are introduced into their chemical composition. Even small amounts of elements such as molybdenum, tungsten or titanium can decrease the corrosion resistance of the coatings significantly at high temperaturc. There is a need, therefore, to obtain coatings free of these detrimental elements by forming coatings of which both the chemical composition and the protective properties would be independent of the substrate chemical composition. That was the reason for development of a protective system by forming the MeCrAlY coatings by the EB-PVD method, plasma spraying and the modified methods of $\mathrm{PtAl}$ and $\mathrm{CrAl}$ coating formation [5]. The development of modern technology and SIP (sputter ion plating) and Arc-evaporation equipment and their modification increased the possibility of producing the MeCrAlY coatings more easily [6-9]. The SIP equipment has certain attractive features such as electron beam evaporation. Furthermore, the equipment is simple. The estimated cost of SIP is also attractive compared with that of plasma sprayed coatings. This is partly because the total cost of SIP is low and also because some processing steps such as post deposition polishing have been eliminated [10]. The best results, however, have been obtained by combining methods of coating based on the MeCrAlY coating deposition followed by the diffusion aluminising $[3,11,23]$. The investigations of protective coatings and the deposition process by Arc and SIP (sputter ion platting) PVD methods for nickel-base alloys and $\gamma$-titanium aluminides were realised in the COST 501 program. $[4,12]$. The PVD method has been used to deposit $\mathrm{PtAl}_{2}$ heat resistant coatings on $\mathrm{TiAl}$ alloys $[13,14]$.

- Intensive investigations on obtaining coatings with low sulphur content (clean coatings) are being conducted [15-18]. The purity of $(\mathrm{Ni}, \mathrm{Pt}) \mathrm{Al}$ is directly related to its oxidation resistance. Ovcr aluminizing of MCrAlY coatings can be one of the ways to obtain coatings without detrimental impurities [18]. Arc-PVD methods allow obtaining clean overaluminising MeCrAlY coatings with very small or without active impurities such sulphur, which are present in standard aluminide coatings The Arc-PVD method gives a lot of possibilities for its industrial application [19-23].

\section{$\underline{\text { Materials }}$}

\section{Experimental}

The nickel base superalloys with the following chemical composition (wt.\%): ZS6K - 9\% Cr, 5\% Co, 4.5\% Al, 5\% W, $10,5 \% \mathrm{Mo},<0,1 \% \mathrm{C}$, balance Ni and CMSX $-4-6.54 \mathrm{Cr}, 10.34 \mathrm{Co}$, 1.03Ti, 4.69Al, 4.06Re, 5.92Ta, 5.9W, 0.5 Mo, Ni-balance were used. Targets for Arc-PVD were produced by a melting method in a Leybold-Heraeus vacuum furnace IS III/5. Then they underwent homogenising in the protective atmosphere at $1373 \mathrm{~K}$ and their chemical composition was determined. The assumed chemical composition of MCrAlY targets was following (wt.\%): $\mathrm{Co}-32$; Ni-38; $\mathrm{Cr}-21$; Al-8; $\mathrm{Y}-1$. The $\mathrm{Al}$ and Al-Si targets were also used. The coatings were made on samples and finally on rotor turbine blades of aircraft engine.

\section{Coatings}

Coatings were obtained by use of two targets in the form of discs with $100 \mathrm{~mm}$ diameter in PVT-550 equipment (Plasma und Vacuum Technik $\mathrm{GmbH}$ ). The samples were made in the form of rod slices with $10 \mathrm{~mm}$ diameter. Before the process the samples were ground on the abrasive papers and then rinsed carefully with detergents at $343 \mathrm{~K}$. After that they were degreased in trichloroethylene with use of ultrasonic and dried carefully. During coating the samples rotated on the special plate, and in addition to it around their own axis. The shortest distance from the target was $150 \mathrm{~mm}$. On the basis of earlier tests the basic coating parameters: current of $80 \mathrm{~A}$, ion cleaning at a bias from $600 \mathrm{~V}$ to $50 \mathrm{~V}$ for 5 minutes, were determined during the whole process. The aluminium deposition process was conducted in the following way: $5 \mathrm{~min}-600 \mathrm{~V}, 80 \mathrm{~min}$. - 50V. The sample temperature was $473 \mathrm{~K}$ during coating. Then the formed coatings were subjected to the diffusion heat treatment process, at 1323K, 4 hours. The obtained coatings underwent examinations of morphology, EDX, structure on a SEM microscope. The distribution of chemical elements was analysed by microprobe analysis.

\section{$\underline{\text { Results }}$}

\section{Coatings on ZS6K alloy}

Depositing the heat resistant coatings on the nickel base superalloys by the Arc-PVD method was divided into two steps: NiCoCrAlY deposition and the aluminium deposition on the NiCoCrAlY coating. After the aluminium deposition process the temperature was increased until the moment of the exothermic reaction initiation between $\mathrm{Al}$ and $\mathrm{Ni}$ contained either in NiCoCrAlY or in the Ni-base superalloys. Those investigations were preceded by an analysis of phenomena during the aluminium deposition on the pure nickel in order to form intermetallic phases by the Arc-PVD method. The final structure formation of the coating takes place in the heat treatment process at $1323 \mathrm{~K}$.

Aluminide coatings. Aluminide coatings, which can be classified into HTLA (High Temperature Low Activity), were obtained. The structure and the EDX analysis results of the coating are presented in fig. 1 (a-c).

The outer zone matrix is a $\beta-\mathrm{NiAl}$ phase with the substochiometric Al content. In the precipitates (point of the analysis) greatly increased molybdenum and tungsten concentration and low aluminium and chromium content was found. Between the $\beta-\mathrm{NiAl}$ outer coating and the substrate there is a transient zone with the elongated prccipitates with the increased content of the highmelting elements. This zone was formed during the heat treatment as a result of dominant diffusion of nickel in $\beta-\mathrm{NiAl}<50 \mathrm{at} . \% \mathrm{AI}$.

Overaluminising NiCoCrAlY. The developed technological principles of obtaining and characteristic of the aluminide and $\mathrm{NiCoCrAlY}$ coatings were the basis of developing the principles of the technology of obtaining the complex MeCrAlY+Al coatings in the Arc-PVD process. The NiCoCrAlY coatings were formed by the Arc-PVD method and then this surface was also covered with aluminium by the same method. That system of coatings was subjected to diffusion heating at $1323 \mathrm{~K}$ for $4 \mathrm{~h}$ in vacuum. The structure and EDX results of the obtained coating is presented in fig. 2 . 


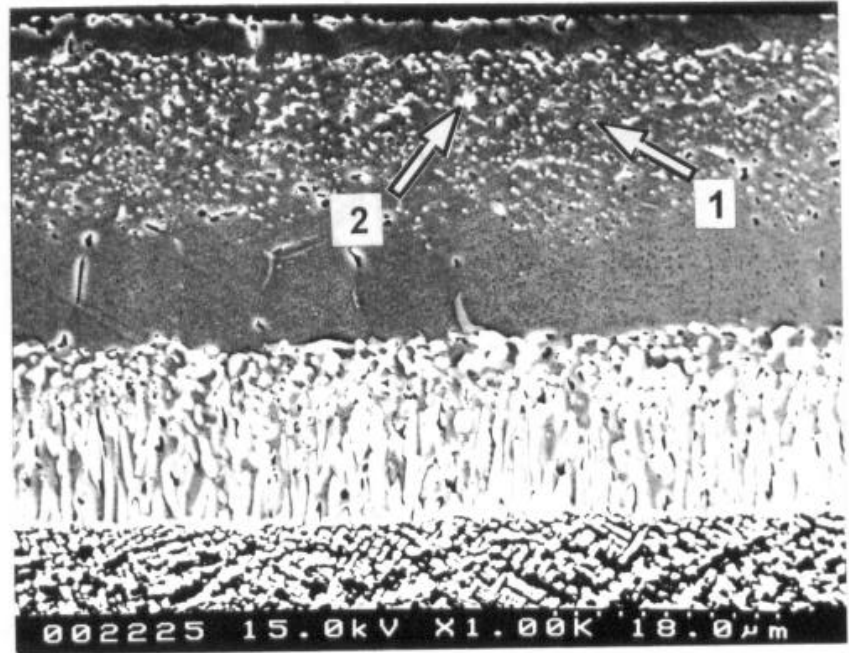

a.
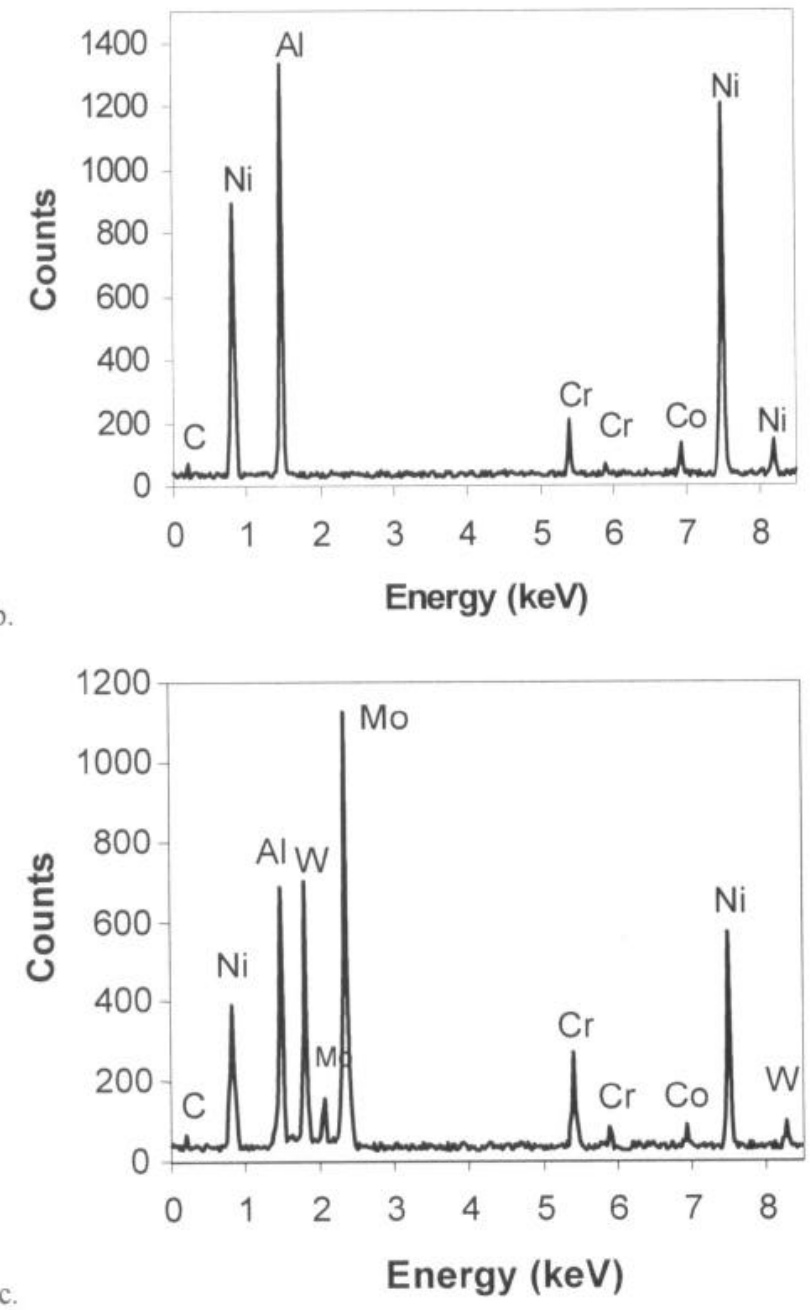

Figure 1: The structure of the $\mathrm{Al}$ coating obtained by the Arc-PVD method on ZS6K alloy, heat treated at $1323 \mathrm{~K} / 4 \mathrm{~h}$ (a) and the EDX analysis in point 1(b) and point 2(c).

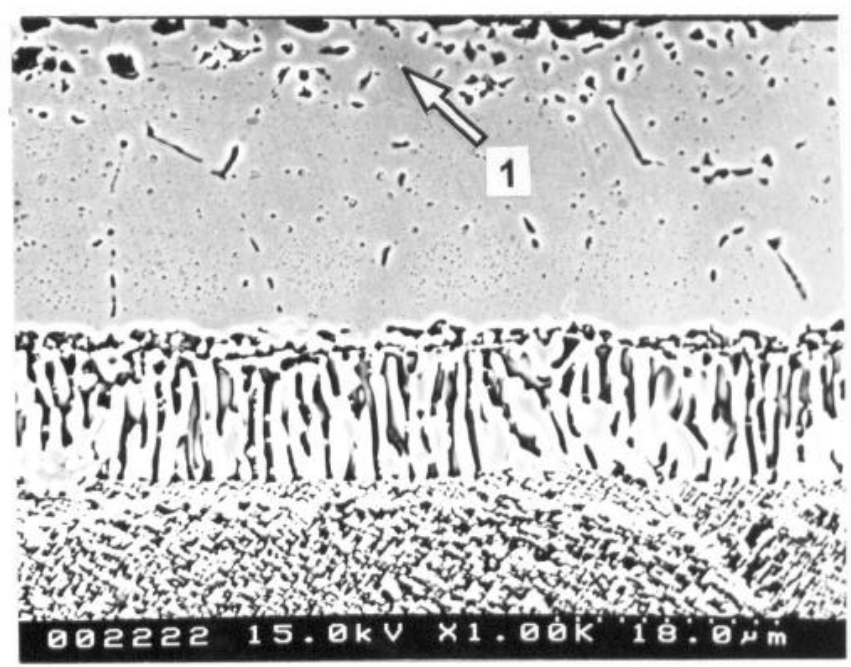

a.

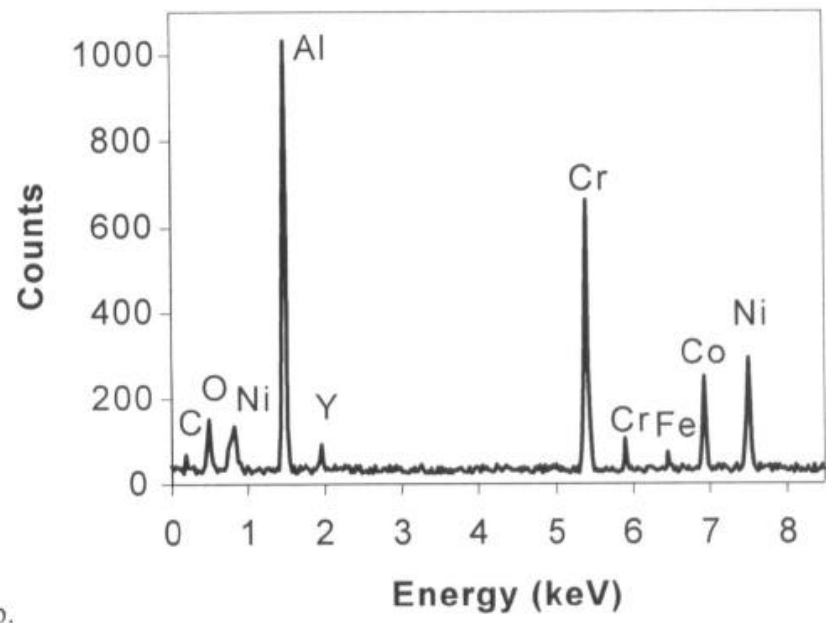

Figure 2: The structure of the $\mathrm{NiCrAlY}+\mathrm{Al}$ coating obtained by the Arc-PVD method on the ZS6K superalloy: the structure of the coating (a), the EDX analysis in point 1 (b).

The coating formed was about $35 \mu \mathrm{m}$ thick. The analysis of the chemical composition of elements in the microareas showed that in spite of heat treatment of the specimens in the vacuum, on the surface there was a very thin oxidised zone in which oxygen, aluminium and yttrium are concentrated. In the 2-4 $\mu \mathrm{m}$ zone below the oxidised zone the amount of aluminium and yttrium decreased and the content of nickel, cobalt and chromium increased.

\section{Coatings on CMSX-4}

Investigations of NiCoCrAlY and $\mathrm{Al}$ coating deposition on the ZS6K cast superalloy experiments and formation of coatings on the CMSX-4 single crystal alloy were made. The coatings were made in the following series: a) NiCoCrAlY deposition on CMSX -4 , heat treatment at $1323 \mathrm{~K}, 4 \mathrm{~h}$, b) NiCoCrAlY deposition on CMSX-4, Al-Si deposition on NiCoCrAlY, exothermic reaction, heat treatment at $1323 \mathrm{~K}, 4 \mathrm{~h}$. The coatings obtained in the particular batches differed in structure and chemical composition. 
NiCoCrAlY coatings. The structure of the NiCoCrAlY coating obtained on the CMSX-4 alloy is presented in Fig.3. The concentration of elements in the characteristic microareas of the coating is presented in table 1 . The coating thickness is $36 \mu \mathrm{m}$. The deep etching revealed characteristic features of the coating structure. It has been shown that the coating consists of elongated discontinuous zones, which are parallel to the surface. Such a structure of the surface results from the deposition process. Specimens were rotated around their own axis and around the axis of the table on which they were placed. Therefore, rotation rate and deposition intensity have significant influence on the coating structure. Single zones have thickness of about 0.5 to $3 \mu \mathrm{m}$. Particular zones have a good bond between each other and they were free of any defects, Between the NiCoCrAlY layer and the substrate there is a thin continuous diffusion zone ensuring good adhesion of the coating to the substrate. This zone is formed in the first stage of the process during ion cleaning, when the deposition parameters have the maximal values and temperature of the specimen surface increases.

The EDX quantitative analysis presented in Table I shows that it is possible to deposit, by the Arc-PVD method, all elements which were present in the target. On the basis of the evaluation of the mean concentration of elements in the coating measured on the whole thickness of the coating and width $3 \mathrm{~mm}$, presented in table I. The following observations were made. The aluminium concentration in the coating is lower than the concentration of this element in the target, the yttrium concentration is also lower, the amount of cobalt increased, whereas amount of nickel is slightly lower. Good compatibility was obtained with chromium content. The average concentration of this element in the target was $21 \mathrm{wt} . \%$ whereas measured in the coating it was $21.82 \mathrm{wt} . \%$, table I. Those results constitute important information for selection of the chemical composition of the target.

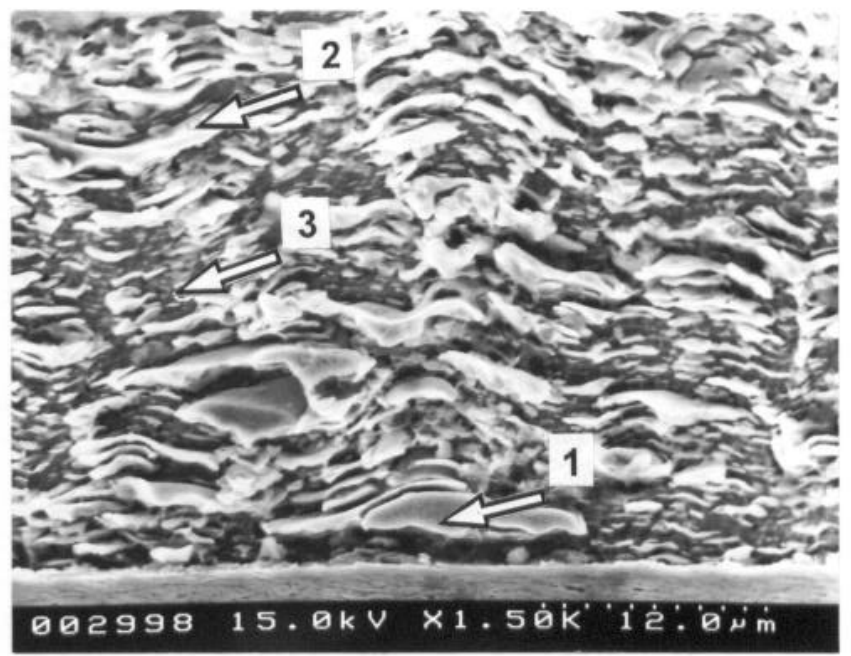

Figure 3: Structure of NiCoCrAlY coating obtained by Arc-PVD method on CMSX-4 alloy.
Aluminide coatings. Aluminide coatings on the CMSX-4 alloy were formed by the Arc-PVD method by deposition of Al-Si from the target with the eutectic composition (11 wt. \% Si). After forming the Al-Si coating by changes in the deposition parameters the temperature was increased on the specimen surface above the melting temperature of the $\mathrm{Al}-\mathrm{Si}$ coating to initiate the exothermic reaction between nickel and aluminium. A coating, being a mixture of phases of strong segregation of elements, with $30 \mu \mathrm{m}$ thickness was obtained. The X-ray diffraction analysis showed that the $\mathrm{NiAl}_{3}$ phase was the matrix. The characteristic feature of this coating is a clear interface with the substrate. The structure of the coating is presented in fig. 4 .

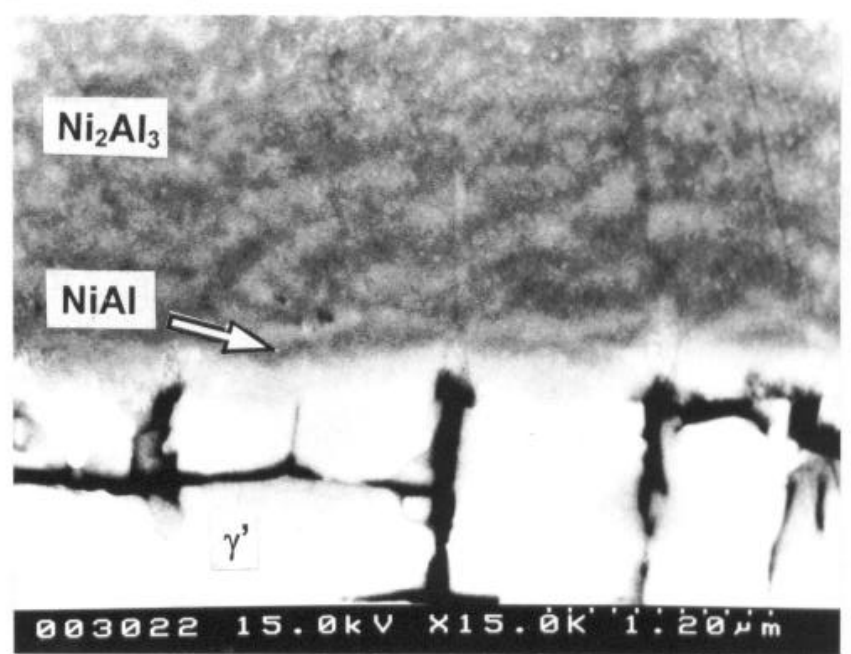

Figure 4: Structure of Al-Si coating on CMSX-4 alloy after the deposition process and exothermic reaction.

The structure of the Al-Si coating obtained by the Arc-PVD method on the CMSX-4 alloy after heat treatment is presented in Fig. 5(a) and (b). The EDX analysis results are shown in Fig. 5(c) and (d). Quantitative analysis results of elements in the microareas are presented in table II.

The structure, presented in fig.5a, has three clear zones formed as a result of diffusion processes in the outer zone and on the boundary with the base alloy. The outer zone is characteristic for high activity coatings of which the matrix of coating is NiAl $>50 \mathrm{at} . \%$ or $\mathrm{Ni}_{2} \mathrm{Al}_{3}$ phase with high concentration of fine precipitates. The morphology of precipitates in the outer zone with the marked points of the quantitative analysis is presented in fig. 5 b.

The diffusion zone is formed as a result of dominant outward nickel diffusion. Morphology and size of precipitates differs considerably from one observed in the outer zone. They are bigger and have more irregular shapes. The similar structure was observed in the coatings on cast alloy. However, below the diffusion zone there is a zone which was absent in the aluminium coatings both on traditional cast superalloys and coatings on the CSMX-4 alloy before the heat treatment, fig. land fig. 4 .

Table I The concentration of elements in the NiCoCrAlY coating on the the CMSX-4 in the point marked in fig. 3

\begin{tabular}{|c|c|c|c|c|c|c|c|c|c|c|}
\hline \multirow{2}{*}{$\begin{array}{l}\text { Measurement } \\
\text { Points }\end{array}$} & \multicolumn{2}{|c|}{ Al. } & \multicolumn{2}{|c|}{$\mathrm{Y}$} & \multicolumn{2}{|c|}{$\mathrm{Cr}$} & \multicolumn{2}{|c|}{ Co } & \multicolumn{2}{|c|}{$\mathrm{Ni}$} \\
\hline & at. $\%$ & wt. \% & at. $\%$ & wt. \% & at. $\%$ & wt. \% & at. $\%$ & wt. $\%$ & at. $\%$ & wt. \% \\
\hline 1 & 10.44 & 5.19 & 0.47 & 0.77 & 16.97 & 16.26 & 33.11 & 35.97 & 38.29 & 41.43 \\
\hline 2 & 17.06 & 8.86 & 0.48 & 0.82 & 15.39 & 15.41 & 34.84 & 39.54 & 30.41 & 34.38 \\
\hline 3 & 2.61 & 1.26 & - & - & 29.72 & 27.61 & 37.02 & 38.98 & 30.65 & 32.15 \\
\hline Average & 8.61 & 4.26 & 0.30 & 0.48 & 22.92 & 21.82 & 35.60 & 38.42 & 32.57 & 35.02 \\
\hline
\end{tabular}




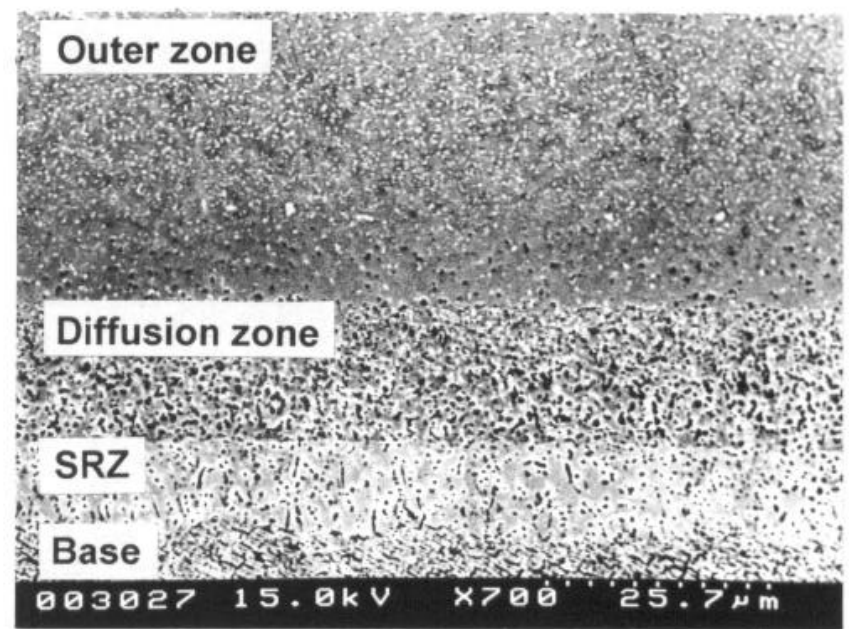

a.

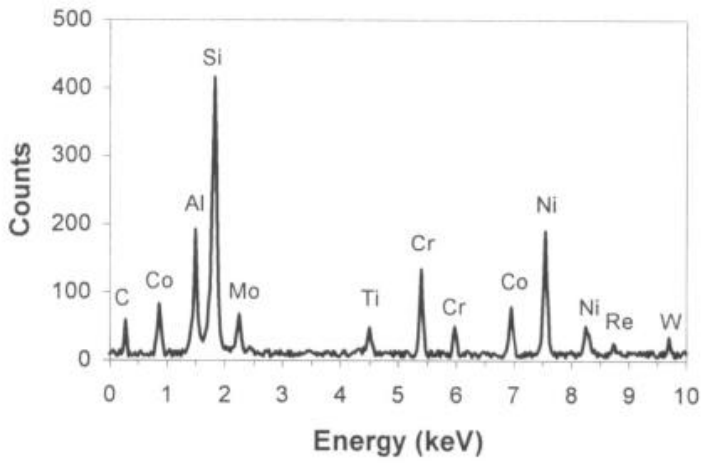

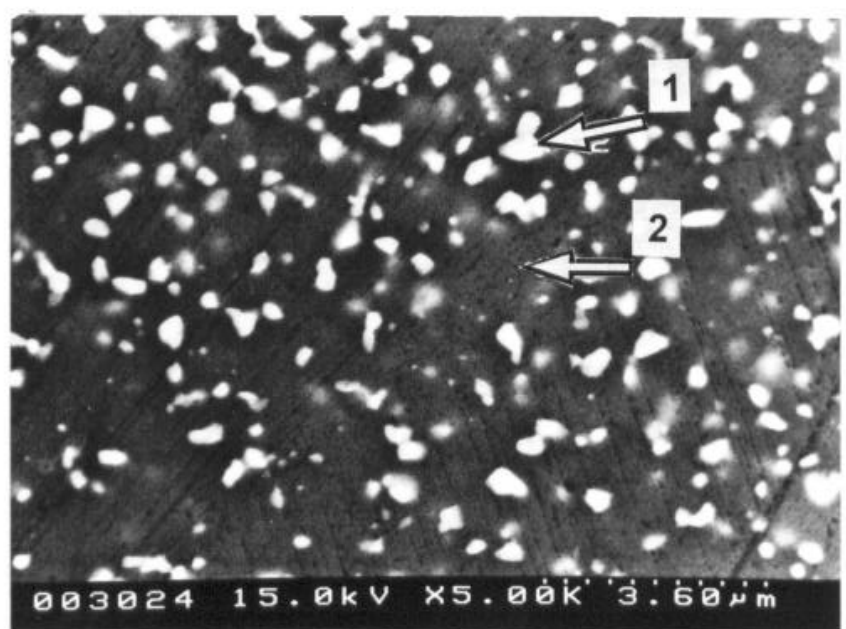

b.

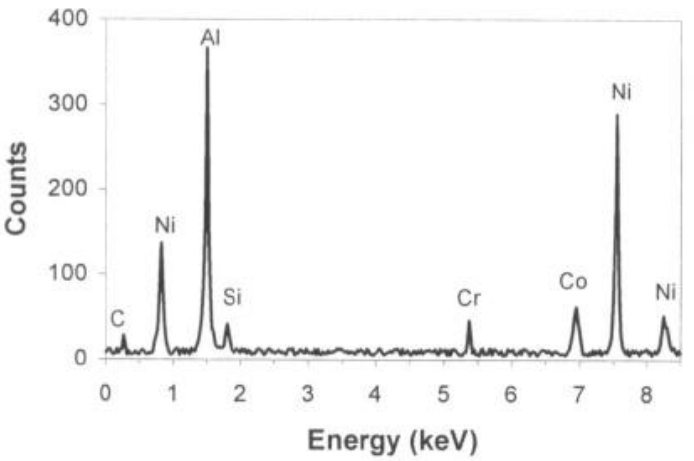

Figure 5: Structure and chemical composition of aluminide coatings obtained by Arc-PVD method and heat treatment at $1323 \mathrm{~K}, 4 \mathrm{~h}$ : the structure of the coating (a), a fragment of the structure with the marked points of the EDX and quantitative analysis (b), the EDX analysis results in point $1(\mathrm{c})$ and point $2(\mathrm{~d})$.

Results of qualitative and quantitative analysis of elements in the coating are presented in fig. 5 (c, d). The analysis of elements in precipitates ( point 1 fig. 5(b)) showed very high contents of $\mathrm{Si}$, $\mathrm{W}, \mathrm{Mo}$ and $\mathrm{Re}$. The Re concentration is particularly high and equals to $15.81 \%$. In the coating matrix besides precipitates the chemical composition is completely different. It is the $\mathrm{NiAl}$ phase composition without such elements as $\mathrm{W}, \mathrm{Mo}$, Re with the small amount of $\mathrm{Cr}$ and $\mathrm{Si}$.

Overaluminising of NiCoCrAlY. The structure of coating obtained in the process of the NiCoCrAlY deposition in the first stage and the aluminium deposition in the second stage, initiation of the exothermic reaction and performing the heat treatment, is presented in fig. 6(a)-(d). As can be seen in the figure 6(a) the coating structure consists of three zones: outer zone bordering with the specimen surface, the diffusion zone bordering with the substrate and the zone belonging to the base alloy with the structure of which characteristic features will be presented in the discussion of results. In the outer zone shown in fig. $6(\mathrm{~b})$ there are precipitates of irregular shapes and size at the surface. The structure of the boundary between the outer zone and diffusion zone is presented in fig. 6(c).
The results of analysis of elements in the microareas of overaluminising of the NiCoCrAlY coating are presented in fig.7 and table III. Precipitates in the outer zone show very high chromium content, being $86 \mathrm{wt} \%$ in point 1 in fig. 6(a) and table III, and in other precipitates in this zone above $59 \mathrm{wt} \%$. In the coating matrix in point 2 , fig. $6(\mathrm{~b})$ and table III, the aluminium concentration is $15 \mathrm{wt} \%$, whereas there was a significant increase in the nickel content and decrease in chromium and cobalt content in comparison with their content in the initial $\mathrm{NiCoCrAlY}$ coating. In this zone chromium was found in the amount of $1.31 \mathrm{wt} . \%$. Besides large precipitates having elevated $\mathrm{Cr}$ concentration there are also fine spherical precipitates which contain not only basic elements but silicon and yttrium as well, fig. 6 (b) point 3 , fig. 7 (c) and table III point 3 . Near the diffusion zone there are also present very fine (white) precipitates marked in fig. 6 (c) as point 5 . Their approximated chemical composition due to accuracy of the microanalysis at such small precipitates, is presented in fig. 7(d) and table III. The analysis of chemical composition on the boundary with the diffusion layer, point 9 , and between precipitates, point 7 fig. $6(\mathrm{c})$ and $7(\mathrm{e}, \mathrm{f})$ and table III revealed significant diversification neither in the qualitative nor in quantitative composition. The white precipitates in the diffusion zone had elevated concentration of tantalum titanium and silicon. 

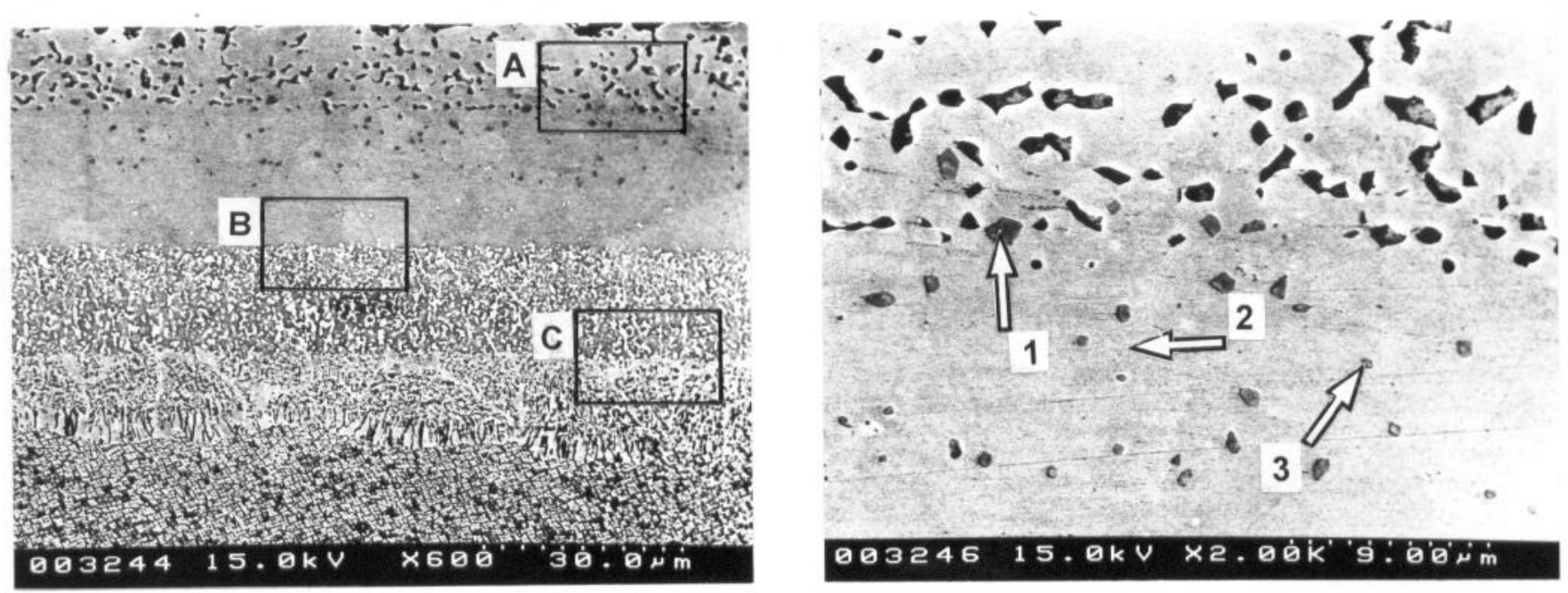

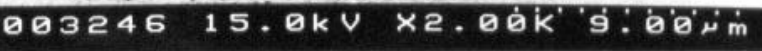
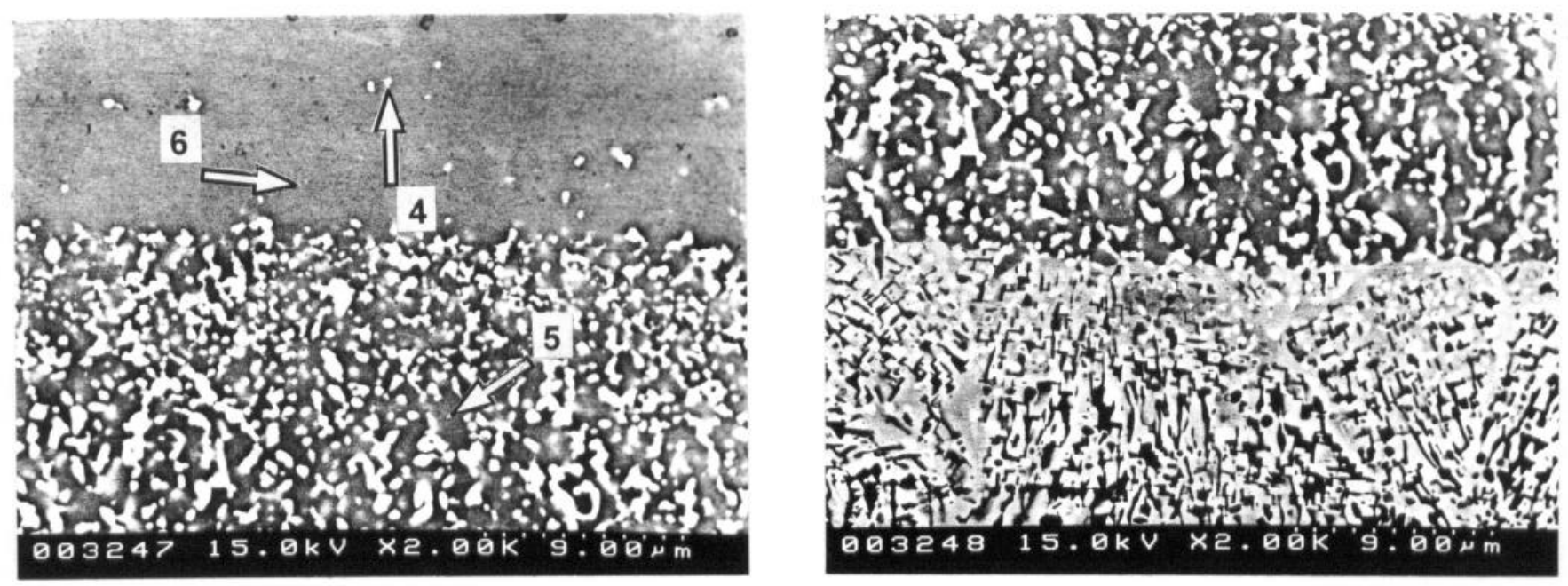

d.

Figure 6: Structure of overaluminising of NiCoCrAlY coatings after heat treatment at $1327 \mathrm{~K}, 4 \mathrm{~h}$ (a), fragment A (b) fragment B (c) fragment $\mathrm{C}(\mathrm{d})$.

Table II Concentration of elements in the aluminide coating shown in fig. 5(b).

\begin{tabular}{|c|c|c|c|c|c|c|c|c|c|c|c|c|c|c|c|c|c|c|}
\hline \multirow[t]{2}{*}{ point } & $\mathrm{A}$ & $\mathrm{Al}$ & $\mathrm{S}$ & & & W & $\mathrm{T}$ & & C & & \multicolumn{2}{|c|}{ Co } & & $\mathrm{Ni}$ & & e & \multicolumn{2}{|c|}{ Mo } \\
\hline & $\%$ & 7 & & 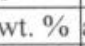 & $\%$ & $w i$ & t. $\%$ & wt. \% & $\%$ & t. $\%$ & at. $\%$ & wt. \% & at. $\%$ & wt. \% & at. $\%$ & wt. $\%$ & t. $\%$ & wt. $\%$ \\
\hline 1 & 13.94 & 6.40 & 22.41 & 10.71 & 4.19 & 13.10 & 1.19 & 0.97 & 9.40 & 8.31 & 9.61 & 9.64 & 32.97 & 732.93 & 4.99 & 15.81 & 1.31 & 2.1 \\
\hline 2 & 36.88 & 21.53 & 1.95 & 1.18 & t & $f$ & 7 & & 3.11 & 3.50 & 6.21 & 7.92 & 51.85 & 565.87 & & & & \\
\hline
\end{tabular}

\begin{tabular}{|c|c|c|c|c|c|c|c|c|c|c|c|c|c|c|c|c|}
\hline \multirow[t]{2}{*}{ point } & \multicolumn{2}{|c|}{$\mathrm{Al}$} & \multicolumn{2}{|c|}{$\mathrm{Si}$} & \multicolumn{2}{|c|}{$\mathrm{Y}$} & \multicolumn{2}{|c|}{$\mathrm{Ti}$} & \multicolumn{2}{|c|}{$\mathrm{Cr}$} & \multicolumn{2}{|c|}{$\mathrm{Co}$} & \multicolumn{2}{|c|}{$\mathrm{Ni}$} & \multicolumn{2}{|c|}{$\mathrm{Ta}$} \\
\hline & at. $\%$ & $\begin{array}{ll}\text { wt. } \% & \text { a } \\
\end{array}$ & at. $\%$ & wt. $\%$ & at. $\%$ & wt. \% & at. $\%$ & wt. $\%$ & at. $\%$ & wt. \% a & at. $\%$ & wt. $\%$ a & at. $\%$ & wt. $\%$ a & at. $\%$ & wt. $\%$ \\
\hline 1 & 3.13 & 1.61 & 5.86 & 3.14 & & -1 & & & 51.18 & \begin{tabular}{l|l|} 
& 50.65 \\
\end{tabular} & \begin{tabular}{|l|}
21.72 \\
\end{tabular} & 24.37 & 18.11 & 20.24 & & \\
\hline 2 & 27.04 & 14.92 & 2.28 & 1.31 & & & & - & 8.45 & 8.98 & 13.74 & 16.56 & 48.49 & 58.23 & & \\
\hline 3 & 27.35 & 15.02 & 2.37 & 1.35 & 1.20 & 2.16 & & & 8.46 & 8.95 & \begin{tabular}{|l|}
13.31 \\
\end{tabular} & 15.96 & 47.32 & 56.55 & & \\
\hline 4 & 10.61 & 3.48 & 15.28 & 5.21 & & & 11.94 & 6.94 & 4.57 & 2.89 & 7.30 & 5.22 & 23.09 & 16.46 & 27.22 & 59.80 \\
\hline 5 & 26.27 & 14.57 & 3.81 & 2.20 & & & 1.03 & 1.02 & 6.86 & 7.33 & 10.68 & 12.93 & 51.36 & 61.96 & & \\
\hline 6 & 27.72 & 15.35 & 2.32 & 1.34 & & & 0.73 & 0.71 & 6.17 & 6.58 & 10.90 & 13.18 & 52.16 & 62.84 & & \\
\hline
\end{tabular}




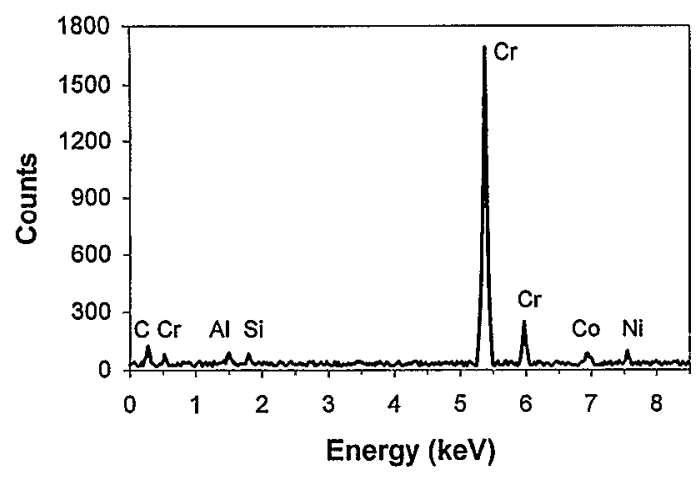

a.

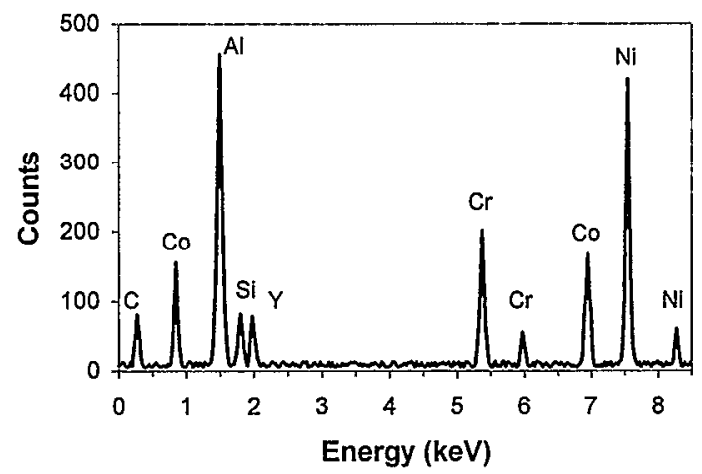

c.

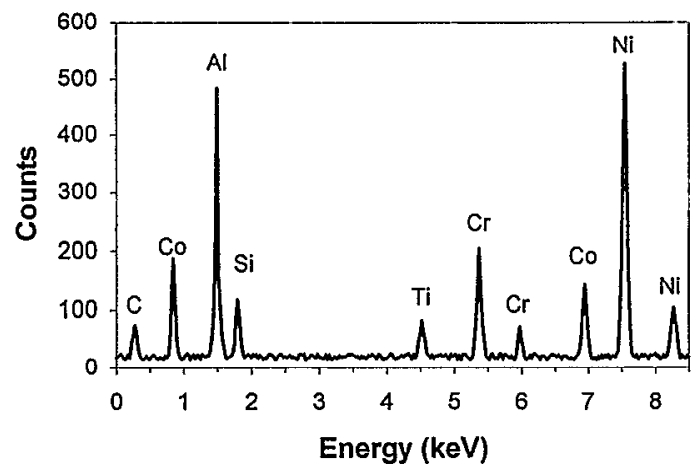

e.

Figure7: Results of EDX analysis in the marked point shown in fig. 6(a), 6(b) and 6(c): point 1(a), 2(b), 3(c), 4(d), 5(e), 6(f).

\section{$\underline{\text { Discussion }}$}

The process of overaluminising of MeCrAlY consists of the following mechanisms assuming as a criterion of classification, the physical phenomena influencing shaping of the structure: 1. the stage of sputtering and deposition of nickel cobalt, chromium, aluminium and yttrium from the target having these elements; 2 . the stage of aluminium and silicon deposition from target with eutectic composition; 3 . the stage of the exothermic reaction between aluminium and nickel contained in the alloy; 4 . the stage of the diffusion growth during diffusion heating in the vacuum furnace.

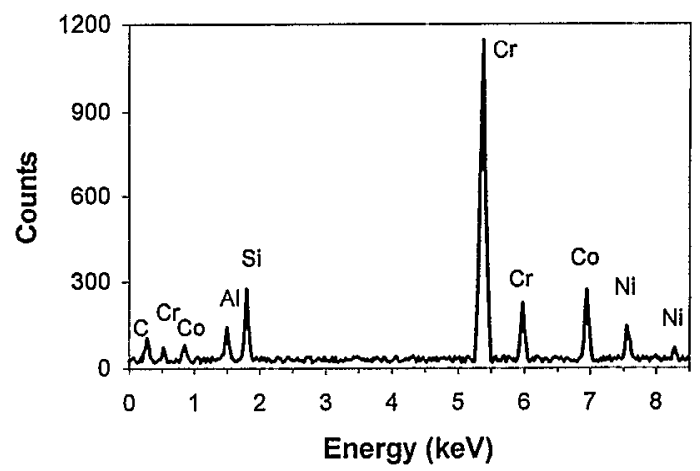

b.

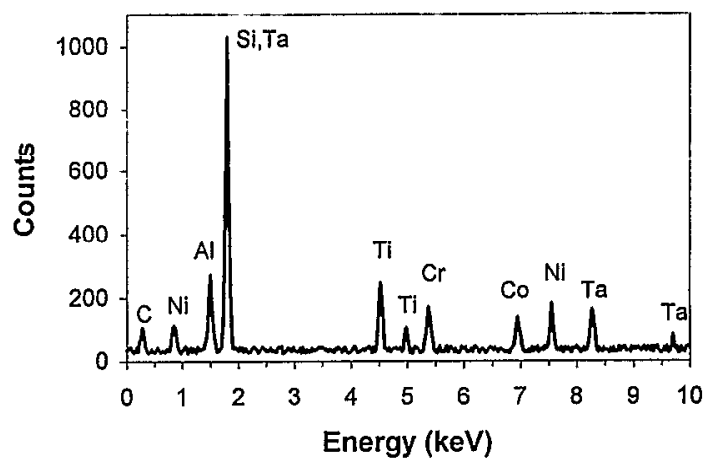

d.

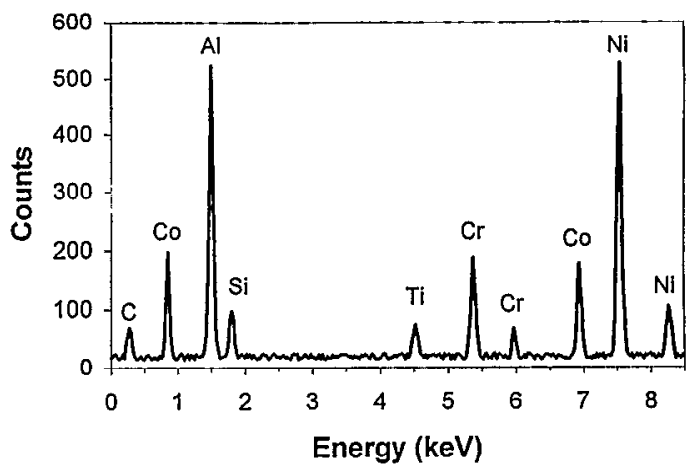

f. 
In the next stage when high efficiency of the process is required to obtain appropriate coating thickness (to $25 \mu \mathrm{m}$ ) the deposition process parameters diverge greatly from the requirements resulting from Thornton's model. Shaping the MeCrAlY coating structure is conditioned by a system of the specimen rotation. Both the rate of the table rotation around main axis and the rotation of specimens around their own axis decides about configuration of the structure. Another factor influencing the MeCrAlY coating structure is a number of sources from which evaporation takes place. Two sources ensure high effectiveness and uniformity of coating.

The Al and AISi deposition by the Arc-PVD method constituted a certain problem, though greater stability of the process was observed during the AISi alloy deposition.

The Al or Al-Si coating immediately after the deposition was remelted on the surface of the alloy or MeCrAlY coating by an increase in the temperature. Magnitude of thermal effect after initiating the exothermic reaction depended on size of specimens and amount of the deposited aluminium (coating thickness). It has been shown that the NiAl coating structure can be shaped by changes in time of maintaining high temperature of the surface in which aluminium can react totally with the surface or the reaction can bc intcrrupted by which the phase composition of coatings can be shaped. However after finishing the exothermic reaction in which heat came only from this reaction supplied from the external source, thin layer of the pure aluminium was always found on the surface.

An analysis of the structure of the coating obtained after the exothermic reaction showed from the surface presence of: phases$\mathrm{NiAl}_{3}, \mathrm{Ni}_{2} \mathrm{Al}_{3}$ and very thin $\mathrm{Ni \Lambda l}$ and $\mathrm{Ni}_{3} \mathrm{Al}$ phase zones on the boundary with the substrate. The further analysis of the Ni-base alloy aluminide coating deals with heat treatment in the vacuum at $1323 \mathrm{~K}$. Firstly, melting of aluminium takes place, after exceeding temperature of $933 \mathrm{~K}, \mathrm{NiAl}_{3}$ melting after exceeding of $1127 \mathrm{~K}$ and diffusion transformation leading to an increase in $\mathrm{Ni}_{2} \mathrm{Al}_{3}$ phase thickness. Further process of the increase in the diffusion layer in the system of $\mathrm{Ni}_{2} \mathrm{Al}_{3}$ should be considered. In a short time as a result of the $\mathrm{Al}$ diffusion to the substrate, the $\mathrm{Ni}_{2} \mathrm{Al}_{3}$ phase changes into $\mathrm{NiAl}>50 \%$ at. Al phase in which there is also dominant $\mathrm{Al}$ diffusion and the layer growths as a result of Al diffusion to the substrate. When the $\mathrm{NiAl}<50 \%$ at. Al phase occurs direction and kinetics of the growth changc. In the $\mathrm{NiAl}$ $<50 \%$ at. Al phase nickel diffusion is dominant but the rate of this process is lower than in high aluminium phases $[25,26]$. From this moment formation process of the so called diffusion zones starts. The nickel diffusion to the substrate changes aluminium and nickel concentration in the outer zone and leads to changes in the phase composition. The temperature and time decided about final structure of the coating. An important problem to be explained is high diversification in the structure of the diffusion zone in the aluminide coatings obtained on the ZS6K and CMSX-4 alloys and the structure of the zone below the diffusion zone observed in the CMSX-4 alloy which was not seen in the coating on the ZS6K alloy.

Microphotograph of aluminide coating presented in fig. 1 shows high thickness of the diffusion zone in comparison with outer one and precipitates perpendicular to the surface and enriched in $\mathrm{Cr}$, $\mathrm{Mo}, \mathrm{W}$ and $\mathrm{Ti}$. Such structure resulted from thermal treatment at $1323 \mathrm{~K}$ for $3 \mathrm{~h}$. The total thickness of the coatings is $41 \mu \mathrm{m}$. The ratio of outer zone thickness to the transient zone can be measure of growth by $\mathrm{Al}$ diffusion inward and $\mathrm{Ni}$ diffusion outward. The ratio of the outer zone thickness to the transient zone in the aluminide coating on the ZS6K alloy was 1.6.
The structure of the coating on the CMSX-4 alloy presented in fig.3 is different from one on the ZS6K alloy for several reasons, among others: it is a Al-Si coating, the thickness of the preliminary deposited Al-Si coating was higher than $\mathrm{Al}$ on the ZS6K alloy, time of heat treatment of the coating on the ZS6K alloy was $3 \mathrm{~h}$ whereas on the CMSX-4 alloy time of heat treatment was $4 \mathrm{~h}$. The factors above had an influence on difference in the ratio of the outer zone thickness to diffusion one. The ratio of thickness in the coatings on the CMSX-4 alloy was 2.75 what shows significant dominance of the aluminium diffusion to the substrate over the outward diffusion of nickel.

Diversification of the structure of the zone directly beneath the diffusion zone from the substrate side requires explanation. As it is seen in fig. 1 , in the coating on the ZS6K alloy directly under the diffusion zone there is a reinforcing $\gamma$ phase whereas in the coating on the CMSX-4 alloy the structure of this zone is different what fig. 5 shows. This is a structure similar to one on the aluminide coatings on the single crystal alloys of the third generation. This type of microstructural instability has been found in superalloys containing high rhenium content. This instability has been termed second reaction zone (SRZ) [27] because it typically occurs beneath the diffusion zone of coatings that are typically applied to superalloys. As it is seen in fig. 5 the SRZ zone beneath the aluminide coating is about $10 \mu \mathrm{m}$.

However, it was not the subject of the detailed analysis in this article, it seems that the SRZ structure is also present beneath overaluminising of NiCoCrAIY coating on the CMAX-4 alloy, fig. $6(\mathrm{a}, \mathrm{c})$.

\section{Conclusion}

The experimental investigations of which results are presented in this work show possibility of forming the diffusion coatings on the nickel base superalloys by the Arc-PVD method.

The concentration of elements in the MeCrAlY coatings differed insignificantly from their concentration in targets. There was a segregation of yttrium into the outer zone in the air thermally treated coatings.

The aluminide coatings, obtained in the Arc-PVD process and heated in vacuum at $1323 \mathrm{~K}$ had the structure similar to the coatings obtained by the pack cementation process. NiAl with precipitates of phases with high concentration of $\mathrm{Mo}, \mathrm{W}, \mathrm{Cr}$ constituted the coating matrix.

In the overaluminising of $\mathrm{NiCoCrAlY}$ obtained by Arc-PVD and heated in vacuum the $(\mathrm{Ni}, \mathrm{Co}, \mathrm{Cr}, \mathrm{Y}) \mathrm{Al}$ phase contained very low amounts of detrimental elements such as Mo and $\mathrm{W}$.

Forming the MeCrAIY coatings by the Arc-PVD method followed by diffusion aluminising or Al-Si process allowed to obtain coatings with the chemical composition without influence of the chemical composition of the base superalloys.

In the coatings obtained by the Arc-PVD method on the CMSX-4 alloy, presence of the SRZ zone (secondary reaction zone) was found and this zone was absent beneath the diffusion zone of coatings on a typical casting ZS6K superalloy.

\section{$\underline{\text { References }}$}

1. G.W.Goward, Materials Science and Technology, March 1986, v. 2, 194-199.

2. R.Mevrel, C.Duret and R.Pichoir, Materials Science and Technology, March 1986, v. 2, 201-205. 
3 E.Restal, M.Malik and L.Singheiser, "High Temperature Alloys For Gas Turbines and Other Application“, Proc. of Conf. held in Liege, Belgium, 6-9 Oct. 1986, (Part.I, ed. by W.Betz, Dordrecht, 1986), 357-404.

4 L.Peichl, D.F.Betridge, "Materials for Adv. Power Engineering", Proc. of a Conference held in Liege, Belgium, 3-6 October 1994, (Part I, Ed. be D. Coutsouradis, 1994), 717-724.

5 R.Streiff, D.H.Boonc, "Corrosion Resistance Modified Aluminide Coatings", Conf. on Coatings and Bimetalics for Energy Systems and Chemical Process Environments, Hilton Head, South Calif. 1984, 159-169.

6 Pat. USA 3978251, Aug 31, 1976.

7 Pat. USA 3754903, Aug 28, 1973.

8 J.R.Nicholls, P.Hancock and L.H.Al Yasiri, Mat. Sc. and Technology, Aug 1989, v. 5, 799-805.

9 J.R.Coad, J.E.Restal, Metals Technology, Dec 1982, v.9, 499-503.

10 J.E.Restal, M.I.Wood, Materials Sci. and Technology, March 1986, Vol. 2, 225-231.

11 P.Hancock, Materials Science and Technology, Mar 1986, 310-313.

12 D.F.Bettridge, R.Wing and S.R.J.Saunders, Materials for Advanced Power Engineering, Proceedings of the $6^{\text {th }}$ Liege Conference vol. 5, (Part II, eds. J.Lecomte -Beckers, F.Schubert, P.J.Ennis, 1998), 961-976.

13 UK Patent Application No. GB 9302978.3, Jan 1993.

14 M.J. Deakin, J.R. Nichols, "Surface coatings on Titanium Alloys to Limit Oxygen Ingress", Materials Science Forum Vol. 251-254 (1997) pp. 777-784.

15 Y.Zhang et.al., "Synthesis and Cyclic Oxidation Behavior of a (Ni,Pt)Al Coating on a Desulfurized Ni-base Superalloy", Metallurgical and Materials Transaction A, V. 30A, October 1999-2679.

16 J.A.Haynes et. al., "Effects of Platinum Additions and sulfur Impurities on the Microstructure and Scale Adhesion Behavior of Single -Phase CVD Aluminide Bond Coatings", Elevated Temperature Coatings: Science and Technology III, (ed. by J.M. Hampikian and Dahotre, The Materials, Metals \& Society, 1999), 185-196.

17 W.Y.Lee et al., "Effects of Sulfur Ompurity on the Scale Adhesion Behavior of a Desulfurized Ni-Based Superalloy Aluminizes by Chemiczal Vapuor Deposition", Metallurgical and Materials Transaction A, v. 29A, March 1998-833.

18 B.M.Warnes, D.C.Punola, "Clean diffusion coatings by chemical vapor deposition", Surface and Coatings Technology $94-95$ (1997) 1-6.

19 J.Vetter et al, "MCrAIY Coatings Deposited by cathodic vacuum arc evaporation", Surf. and Coatings Technology, $68 / 69$ (1994) 27-31.

20 O.Knotek et al, "Arc evaporation of multicomponent MCrAlY cathodes", Surface and Coatings Technology, 74-75 (1995) 118-122.

21 L.Swadźba et al, "McCrAlY Coatings Obtaincd by Arc PVD and Pack Cementation Processes on Nickel Base Superalloys", in High Temperature Corrosion and Protection of Materials 4, Part 2, (R.Streiff et al., Editors, Materials Science Volumes, Trans Tech Publications, 1996), 793.

22 L.Swadźba, B.Formanek and A.Maciejny, "Modified heatresistant protective coatings for nickel-base superalloys", International Journal of Materials and Product Technology, v.8, No 2,3,4, 1993.

23 L.Swadźba et al., Materials for Advanced power Engineering, Proceedings of the $6^{\text {th }}$ Liege Conference vol. 5, Part III, (eds. J.Lecomte-Beckers, F.Schubert, P.J.Ennis, 1998), 1513-1522.

24 J.A. Thornton, Journal of Vacuum Science and Technology, A4(6), 1986, 3059-3065.

25 M.M.P.Janssen, Metallurgical Transactions, v. 4, June 1973, 1623.

26 M.M.P.Janssen, G.D.Rieck, Trans. TMS-AIME, 1967, vol. 239, 1372-85.

27 W.S. Walston et al., "A New Type of Microstructural Instability in Superalloys - SRZ.", Superalloys 1996, ed. R.D.Kissinger et al., (TMS 1996), 9-18. 